\title{
International Comparison of Data from International Clinical Trials Registry Platform-Registered Clinical Trials*
}

\author{
Hitoshi Fujii, Keiko Yukawa, Hajime Sato \\ Department of Health Policy and Technology Assessment, National Institute of Public Health, Wako, Saitama, Japan \\ Email: fuji@niph.go.jp, k.yukawa@niph.go.jp, hsato@niph.go.jp
}

How to cite this paper: Fujii, H., Yukawa, K. and Sato, H. (2016) International Comparison of Data from International Clinical Trials Registry Platform-Registered Clinical Trials. Health, 8, 1759-1765. http://dx.doi.org/10.4236/health.2016.815169

Received: October 31, 2016

Accepted: December 11, 2016

Published: December 14, 2016

Copyright $\odot 2016$ by authors and Scientific Research Publishing Inc. This work is licensed under the Creative Commons Attribution International License (CC BY 4.0).

http://creativecommons.org/licenses/by/4.0/

\begin{abstract}
Objectives: Our aim was to clarify the study characteristics of countries that have registered clinical trials studies and to calculate the percentage of clinical trials that were registered in each country's registry, and try to find and evaluate the factors determining that percentage. Design and Methods: The present study is a cross-sectional study using data from clinical trials registered from January 1, 2011, to December 31, 2015. Only countries with more than 2000 registered trials were included for further study. Ten countries met that criterion: United States, Japan, Iran, Australia, New Zealand, China, India, Germany, United Kingdom, and Netherland. The percentage of clinical trials that were registered in each country's registry was calculated, and the factors determining that percentage were sought and analyzed through an exploratory approach. Results: The chi-squared test of independence indicated that the rate of clinical trial registration significantly differed between countries. From the adjusted standardized residuals, the percentage of clinical trials that were registered in the country of origin was higher in the United States, India, Japan, and Australia/New Zealand than in the European Union and China. Conclusion: The United States requires that informed consent documents for clinical trials contain clinical trial registration numbers from ClinicalTrials.gov, which could be the reason for the extremely high percentage of registered clinical trials (94\%). Since the European Union does not have this requirement, clinical trials conducted in the European Union do not have to be registered in the countries in which they are conducted.
\end{abstract}

\section{Keywords}

Clinical Trial Registration, International Clinical Trials Registry Platform

\footnotetext{
${ }^{*}$ International comparison of data from ICTRP-registered clinical trials.
} 


\section{Introduction}

Ever since GlaxoSmithKline concealed negative data of Paxil in the United States in 2004, establishing a system for registering and releasing clinical trial information before the start of a study has become a global requirement. Around 2006, clinical trial registration agencies formed in various countries to meet this requirement. The World Health Organization (WHO) Primary Registries was created to certify registration agencies such as ClinicalTrial.gov in the USA and the EU Clinical Trials Register in the EU, which regularly provide the International Clinical Trial Registry Platform (ICTRP) with information about clinical trials. The ICTRP integrates data from various countries and releases them in a downloadable format. Research studies based on that data include a number of systematic reviews or meta-analyses focused on specific diseases, but few studies have been conducted to analyze the tendency between clinical trials across countries.

Fabio et al. [1] analyzed the number of clinical trial-related sites per million people for 25 countries. Barrios et al. [2] analyzed the causes of the globalization of cancer-related clinical trials. Numerous other studies focused on the differences between clinical trials supported by different sponsors. Atal et al. [3] investigated the ratios of industry-sponsored clinical trials to non-industry-sponsored clinical trials in different countries, and analyzed the relationship between those ratios and income levels. Murthy et al. [4] reported that clinical trials in lower income countries tended to have more Phase 3 and 4 trials with larger numbers of subjects and longer trial periods compared with higher income countries. Bourgeois et al. reached the same conclusions. In addition, Bourgeois et al. [5] pointed out that industry-sponsored studies have a higher percentage of papers published compared with government-sponsored studies. In contrast, Ross et al. [6] noted that the percentage of industry-sponsored studies was lower than that of non-industry or nongovernment-sponsored studies, but the percentage of industry-sponsored studies did not significantly differ from government-sponsored studies.

Our aim was to clarify the study characteristics of countries that have registered clinical trials studies and to calculate the percentage of clinical trials that were registered in each country's registry, and try to find and evaluate the factors determining that percentage.

\section{Method}

Procedures of registration and publication are different by country. For example Clinical.gov requires the user to enter some data published on the web. Once entry of data is finished, the quality assurance staff of ClinicalTrials.gov checks it. Users are permitted to publish data by modifications requested to the staff. On the other hand, in Japan there is a limited check on registered data, and registered data is released as it is.

The only common rule around world is to register Minimum Data set as mandated by WHO (http://www.who.int/ictrp/network/trds v1.2/en/). The Minimum data set contains recruitment status, health condition, date of first enrollment, Study type, In- 
tervention, primary outcome, exclude criteria, primary sponsor, et al. Data registered in all primary registries are periodically sent to ICTRP.

The present study is a cross-sectional study using registered data from clinical trials. All data from clinical trials registered from January 1, 2011, to December 31, 2015, were downloaded from the WHO's ICTRP. The number of clinical trials totaled 168,001. Only countries with more than 2,000 registered trials were included for further study (Table 1). 2000 is a number that can stand for statistical analysis. Ten countries met that criterion: United States, Japan, Iran, Australia, New Zealand, China, India, Germany, United Kingdom, and Netherland.

Australia and New Zealand were treated as single category, since data from both countries are registered in the same registry. Japan has three registries: University Hospital Medical Information Network, Japan Pharmaceutical Information Center, and Japan Medical Association Center for Clinical Trials. Data from these registries are integrated by the National Institute of Public Health. Countries in the European Union share a common registry (the EU Clinical Trials Register).

The percentage of clinical trials that were registered in each country's registry was calculated, and the factors determining that percentage were sought and analyzed through an exploratory approach. We make a table for each country whether or not it was registered in each country and analyzed by the chi-squared test of independence.

Table 1. Clinical trials registered by primary registries (2011-2015).

\begin{tabular}{cccc}
\hline Country & Abbreviations & Source Register & Number \\
\hline United States of America & US & ClinicalTrials.gov & 102,634 \\
Japan & JP & JPRN & $\mathbf{1 6 , 4 5 3}$ \\
EU & EU & EU Clinical Trials Register & $\mathbf{8 7 2 9}$ \\
Iran & IR & IRCT & $\mathbf{8 5 3 2}$ \\
Australia/New Zealand & AU/NZ & ANZCTR & 6596 \\
China & CH & ChiCTR & 6458 \\
India & IN & CTRI & 4723 \\
United Kingdom & UK & ISRCTN & 4469 \\
Germany & DE & German Clinical Trials Register & 2952 \\
Netherland & NE & Netherlands Trial Register & 2835 \\
Korea & KR & CRIS & 1531 \\
Brazil & BR & REBEC & 697 \\
Thai & TH & TCTR & 587 \\
Pan Africa & - & PACTR & 567 \\
Sri Lanka & LK & SLCTR & 129 \\
Cuba & CU & RPCEC & 109 \\
\hline
\end{tabular}

${ }^{\star}$ Bold indicates the subject of study. 


\section{Result}

We analyzed 111,741 data of the top 10 countries out of 168,001 data (66.5\%). It should be noted that $0.5 \%$ of the following results contain duplicate registrations. The numbers of registered clinical trials for various countries are shown in Table 2. The numbers of clinical trials in the United States and other advanced countries were significantly greater than in other countries. However, many trials were also conducted in China and India.

Table 3 shows the relationship between countries conducting clinical trials and certified registries. Since there were a considerable amount of data, results of the chisquared tests tended to be statistically significant. The chi-squared test of independence indicated that the rate of clinical trial registration significantly differed between countries.

From the adjusted standardized residuals in Table 4, the percentage of clinical trials that were registered in the country of origin was higher in the United States, India, Japan, and Iran than in the European Union and China $(\mathrm{p}<0.00)$.

As the adjusted residuals in the chi-square test are normally distributed, it is considered that there is a statistically significant difference when the absolute value exceeds approximately 2 .

\section{Discussion}

The United States, European Union, and Japan follow guidelines set by the International Conference on Harmonization of Technical Requirements for Registration of Pharmaceuticals for Human Use, which defines international standards for new drug approval reviews and methods of clinical trials. However, all three have modified the standards. For instance, the United States requires that informed consent documents for clinical trials contain clinical trial registration numbers from ClinicalTrials.gov, which could be the reason for the extremely high percentage of registered clinical trials (94\%). Since the European Union does not have this requirement, clinical trials conducted in the European Union do not have to be registered in the countries in which they are conducted, nor do they have to be registered with the EU Clinical Trials Register. Therefore, when new drug applications are anticipated in US markets, the trials are

Table 2. Clinical trials by the country of implementation.

\begin{tabular}{|c|c|c|c|c|c|c|c|c|c|}
\hline \multirow{2}{*}{ Years } & \multicolumn{9}{|c|}{ Country } \\
\hline & US & JP & $\mathrm{CH}$ & IN & $\mathrm{DE}$ & UK & $\mathrm{NE}$ & AU/NZ & IR \\
\hline 2011 & 7835 & 2749 & 1478 & 1159 & 2349 & 1788 & 1393 & 1459 & 1246 \\
\hline 2012 & 8088 & 3256 & 1940 & 1197 & 2140 & 1984 & 1434 & 1482 & 1537 \\
\hline 2013 & 8397 & 3646 & 2253 & 1236 & 2080 & 1987 & 1510 & 1562 & 1784 \\
\hline 2014 & 8928 & 3994 & 2679 & 1256 & 2243 & 2133 & 1634 & 1535 & 2051 \\
\hline 2015 & 8636 & 4919 & 3302 & 1350 & 2837 & 2398 & 1709 & 1786 & 2346 \\
\hline Total & 41,884 & 18,564 & 11,652 & 6198 & 11,649 & 10,290 & 7680 & 7824 & 8964 \\
\hline
\end{tabular}




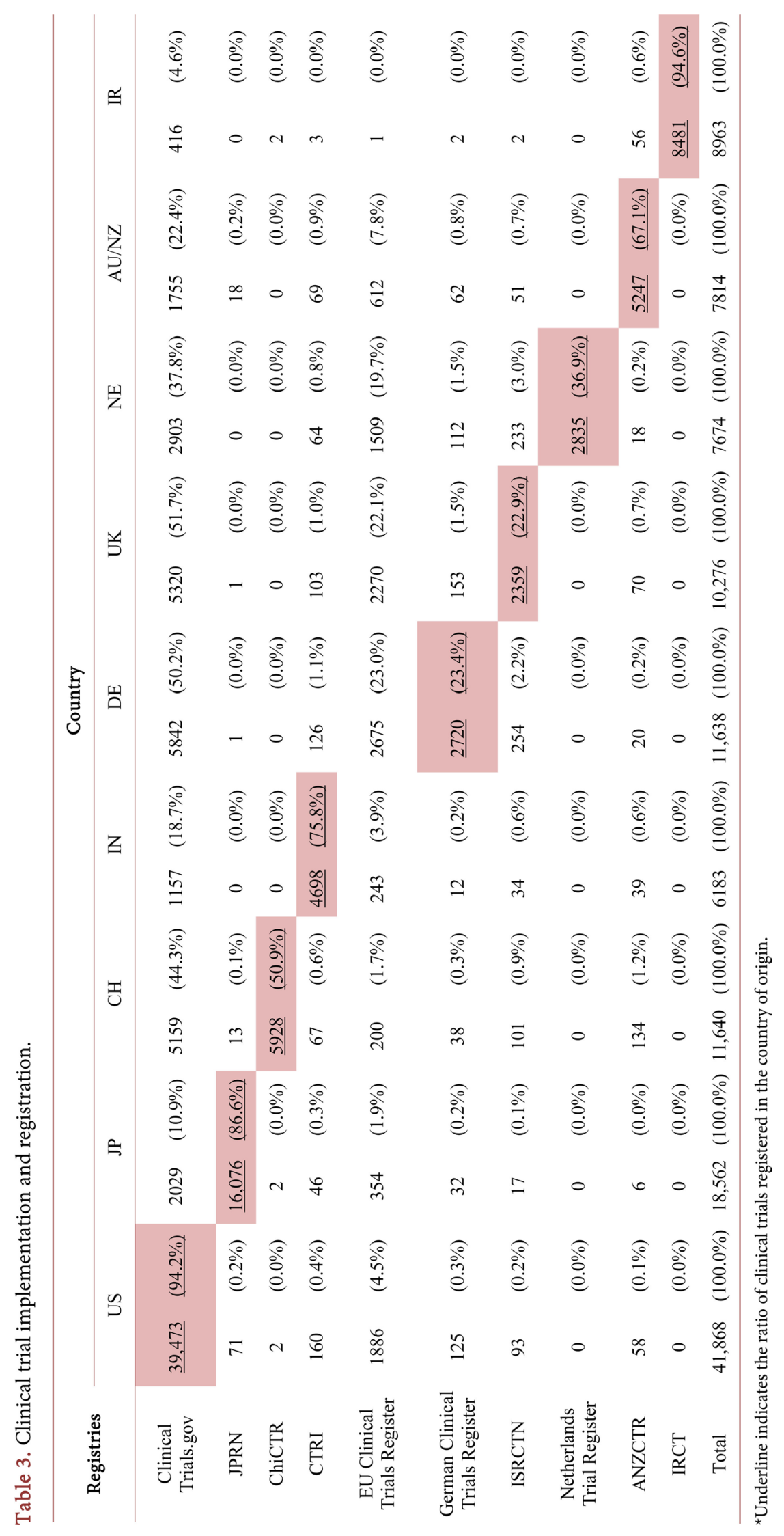


Table 4. Registration of clinical trials to home registries.

\begin{tabular}{cccccc}
\hline \multirow{2}{*}{ Country } & \multicolumn{2}{c}{ Home registry } & \multicolumn{2}{c}{ Other registries } & \\
\cline { 2 - 4 } & $\begin{array}{c}\text { Number of } \\
\text { clinical trials }\end{array}$ & $\begin{array}{c}\text { adjusted standardized } \\
\text { residual }\end{array}$ & $\begin{array}{c}\text { Number of } \\
\text { clinical trials }\end{array}$ & $\begin{array}{c}\text { adjusted standardized } \\
\text { residual }\end{array}$ & Total \\
\hline US & 39,473 & 131.1 & 2395 & -131.1 & 41,868 \\
JP & 16,076 & 52.2 & 2486 & -52.2 & 18,562 \\
CH & 5928 & -48.5 & 5712 & 48.5 & 11,640 \\
IN & 4698 & 9.7 & 1485 & -9.7 & 6183 \\
DE & 2720 & -117 & 8918 & 117 & 11,638 \\
UK & 2359 & -110.2 & 7917 & 110.2 & 10,276 \\
NE & 2835 & -66.5 & 4839 & 66.5 & 7674 \\
AU/NZ & 5247 & -6.6 & 2567 & 6.6 & 7814 \\
IR & 8481 & 52 & 482 & -52 & 8963 \\
\hline
\end{tabular}

${ }^{* *} \mathrm{p}<0.05$; The chi-squared test of independence.

registered with ClinicalTrials.gov, which accounts for the high registration rate of EU countries at ClinicalTrials.gov.

The registration rate could also have been affected by ease of registration. The EU Clinical Trials Register has a hierarchical system with five or more layers and many input items. It is much more complicated compared with registries in the United States and Japan. The Japanese registry has fewer input parameters and almost no check for registration is ever made. Admittedly, our analysis could have been affected by language barriers, since some studies in the Japanese registry were written entirely in Japanese.

Furthermore, the Australian New Zealand Clinical Trials Registry in Australia/New Zealand, Chinese Clinical Trial Register in China, and Clinical Trials Registry in India require only 20 input parameters, the minimum data set mandated by the WHO. Hence, registration in these registries is extremely easy. We therefore conclude that it is easiest to register in the country of origin if the clinical trial is not conducted through international collaboration.

Previous studies including Fabio et al. [1] mainly analyzed the sponsors of clinical trials. In this research, we focused on the choice of register that the previous research did not pay attention to.

Finally we explain the limitation of this research. Although the country is included in the Minimum Data Set mandated by WHO, there are many missing values (9448 trials). Also, there are many descriptions such as "except Japan" and "multinational" that do not know the specific country name. Therefore, although the number of clinical trials is large, expected error rate cannot be achieved.

\section{References}

[1] Thiers, F.A., Sinskey, A.J. and Berndt, E.R. (2008) Trends in the Globalization of Clinical 
Trials. Nature Reviews Drug Discovery, 7, 13-14. https://doi.org/10.1038/nrd2441

[2] Barrios, C.H., Werutsky, G. and Martinez-Mesa, J. (2015) The Global Conduct of Cancer Clinical Trials: Challenges and Opportunities. American Society of Clinical Oncology. Educational Book, e132-139. https://doi.org/10.14694/EdBook AM.2015.35.e132

[3] Atal, I., Trinquart, L., Porcher, R. and Ravaud, P. (2015) Differential Globalization of Industry- and Non-Industry-Sponsored Clinical Trials. PLoS One, 10, e0145122.

https://doi.org/10.1371/journal.pone.0145122

[4] Murthy, S., Mandl, K.D. and Bourgeois, F.T. (2015) Industry-Sponsored Clinical Research outside High-Income Countries: An Empirical Analysis of Registered Clinical Trials from 2006 to 2013. Health Research Policy and Systems, 13, 28.

https://doi.org/10.1186/s12961-015-0019-6

[5] Bourgeois, F.T., Murthy, S. and Mandl, K.D. (2010) Outcome Reporting among Drug Trials Registered in ClinicalTrials.gov. Annals of Internal Medicine, 153,158-166. https://doi.org/10.7326/0003-4819-153-3-201008030-00006

[6] Ross, J.S., Mulvey, G.K., Hines, E.M., Nissen, S.E. and Krumholz, H.M. (2009) Trial publication after Registration in ClinicalTrials.Gov: A Cross-Sectional Analysis. PLOS Medicine, 6, e1000144. https://doi.org/10.1371/journal.pmed.1000144

Submit or recommend next manuscript to SCIRP and we will provide best service for you:

Accepting pre-submission inquiries through Email, Facebook, LinkedIn, Twitter, etc.

A wide selection of journals (inclusive of 9 subjects, more than 200 journals)

Providing 24-hour high-quality service

User-friendly online submission system

Fair and swift peer-review system

Efficient typesetting and proofreading procedure

Display of the result of downloads and visits, as well as the number of cited articles

Maximum dissemination of your research work

Submit your manuscript at: http://papersubmission.scirp.org/

Or contact health@scirp.org 